\title{
Article \\ Effect of Pd on the Electrocatalytic Activity of Pt towards Oxidation of Ethanol in Alkaline Solutions
}

\author{
Salma Jadali ${ }^{1}$, Mohammad Ali Kamyabi ${ }^{1,2, * \mathbb{D}}$, José Solla-Gullón ${ }^{2}$ (D) and Enrique Herrero ${ }^{2, *(\mathbb{D})}$ \\ 1 Department of Chemistry, Faculty of Science, University of Zanjan, Zanjan 45371-38791, Iran; \\ salmajdali@gmail.com \\ 2 Instituto de Electroquímica, Universidad de Alicante, Apartado 99, E-03080 Alicante, Spain; jose.solla@ua.es \\ * Correspondence: makamyabi@gmail.com (M.A.K.); herrero@ua.es (E.H.); \\ Tel.: +98-(24)-33052617 (M.A.K.); +34-965909814 (E.H.); Fax: +98-(24)-32033228 (M.A.K.)
}

Citation: Jadali, S.; Kamyabi, M.A.; Solla-Gullón, J.; Herrero, E. Effect of Pd on the Electrocatalytic Activity of $\mathrm{Pt}$ towards Oxidation of Ethanol in Alkaline Solutions. Appl. Sci. 2021, 11, 1315. https://doi.org/10.3390/ app11031315

Received: 23 December 2020

Accepted: 26 January 2021

Published: 1 February 2021

Publisher's Note: MDPI stays neutral with regard to jurisdictional claims in published maps and institutional affiliations.

Copyright: (c) 2021 by the authors. Licensee MDPI, Basel, Switzerland. This article is an open access article distributed under the terms and conditions of the Creative Commons Attribution (CC BY) license (https:// creativecommons.org/licenses/by/ $4.0 /)$.

\begin{abstract}
The understanding of electrocatalytic activity and poisoning resistance properties of $\mathrm{Pt}$ and Pd nanoparticles, recognized as the best electrocatalysts for the ethanol oxidation reaction, is an essential step for the commercialization of direct ethanol fuel cells (DEFCs). In this paper, mono and bimetallic Pt and Pd nanoparticles with different atomic ratios have been synthesized to study their electrocatalytic properties for an ethanol oxidation reaction in alkaline solutions. The different nanoparticles were physiochemically characterized by transmission electron microscopy (TEM), energy-dispersive X-ray spectroscopy (EDX), X-ray diffraction (XRD), and X-ray photoelectron spectroscopy (XPS). The electrochemical characterization was performed by cyclic voltammetry and chronoamperometry measurements. The electrochemical measurements indicate that Pt nanoparticles have much higher electrocatalytic activity for ethanol oxidation than Pd nanoparticles. The studies with bimetallic PtPd nanoparticles showed a significant impact of their composition on the ethanol oxidation. Thus, the highest electrocatalytic activity and poisoning resistance properties were obtained for $\mathrm{Pt}_{3} \mathrm{Pd}_{2}$ nanoparticles. Moreover, this study demonstrates that the poisoning of the catalyst surface through ethanol oxidation is related to the prevalence of the acetaldehyde-acetate route and the polymerization of acetaldehyde through aldol condensation in the alkaline media.
\end{abstract}

Keywords: direct ethanol fuel cells; electrocatalyst; PtPd nanoparticles; antipoisoning property; acetaldehyde-acetate route

\section{Introduction}

Direct alcohol fuel cells (DAFCs) have been considered as an alternative source of energy for many electronic devices [1,2]. DAFCs present several advantages over lithiumion batteries (LIBs), which are normally used in these electronic devices, and hydrogenfeed polymer electrolyte membrane fuel cells (PEMFCs). LIBs cannot be used as the power source in portable devices or even in stationary devices where an electrical energy source is not available. Under these conditions, DAFCs are the best choice for such devices $[3,4]$. Although the theoretical voltage of DAFCs and PEMFCs are approximately the same, alcohols present with fewer problems of storage and transportation. Alcohols have a high energy density $\left(4000-7000 \mathrm{Wh} \mathrm{L}^{-1}\right)$ which is similar to those of hydrocarbons (9800 Wh L $\left.{ }^{-1}\right)$ while the power density of hydrogen $\left(180 \mathrm{Wh} \mathrm{L}^{-1}\right)$ is lower than DAFCs [5]. These properties reflect the theoretical superiority of DAFCs over PEMFCs. Different kinds of alcohols can be used as fuel in DAFCs, each of them has its own advantages and disadvantages [6]. Although there are studies on the use of ethylene glycol [7], propanol [8], and butanol [9] as fuels in DAFCs, the most widespread alcohol-based fuels are methanol and ethanol [10-15]. In addition to the high energy density and nontoxicity of ethanol, the balance of $\mathrm{CO}_{2}$, the most common greenhouse gas, in the environment is preserved during ethanol oxidation because ethanol can be obtained from biomass. Thus, there is a circulation between ethanol consumption and ethanol production through the fermentation process of 
agricultural products [6]. Regarding its oxidation mechanism on platinum electrodes, it has been well confirmed that ethanol oxidation reaction (EOR) can take place through a parallel pathway [16-18]. In the first route (blue arrows in Figure 1), the so-called C2 pathway, the $\mathrm{C}-\mathrm{C}$ bond is not broken, and ethanol is first oxidized to acetaldehyde, which can be further oxidized to acetic acid (or acetate in alkaline solution) $[19,20]$. This route exchanges four electrons and releases only one-third of the formal energy density of ethanol. The release of the whole energy stored in ethanol is obtained through the $\mathrm{C} 1$ pathway with the exchange of twelve electrons. This route (green arrows in Figure 1) proceeds through the breaking of the $\mathrm{C}-\mathrm{C}$ bond in the early stages of the oxidation process and produces adsorbed $\mathrm{CO}$ which can be further oxidized to $\mathrm{CO}_{2}$ (or carbonate in alkaline solution). $\mathrm{CO}$ is considered a poison intermediate because it is strongly adsorbed on the surface (blocking surface sites) and its oxidation requires high overpotentials. The efforts that expedite oxidation of $\mathrm{CO}$ to $\mathrm{CO}_{2}$ and decrease the potential of $\mathrm{CO}$ oxidation remarkably improve the electrocatalytic activity towards EOR [20].

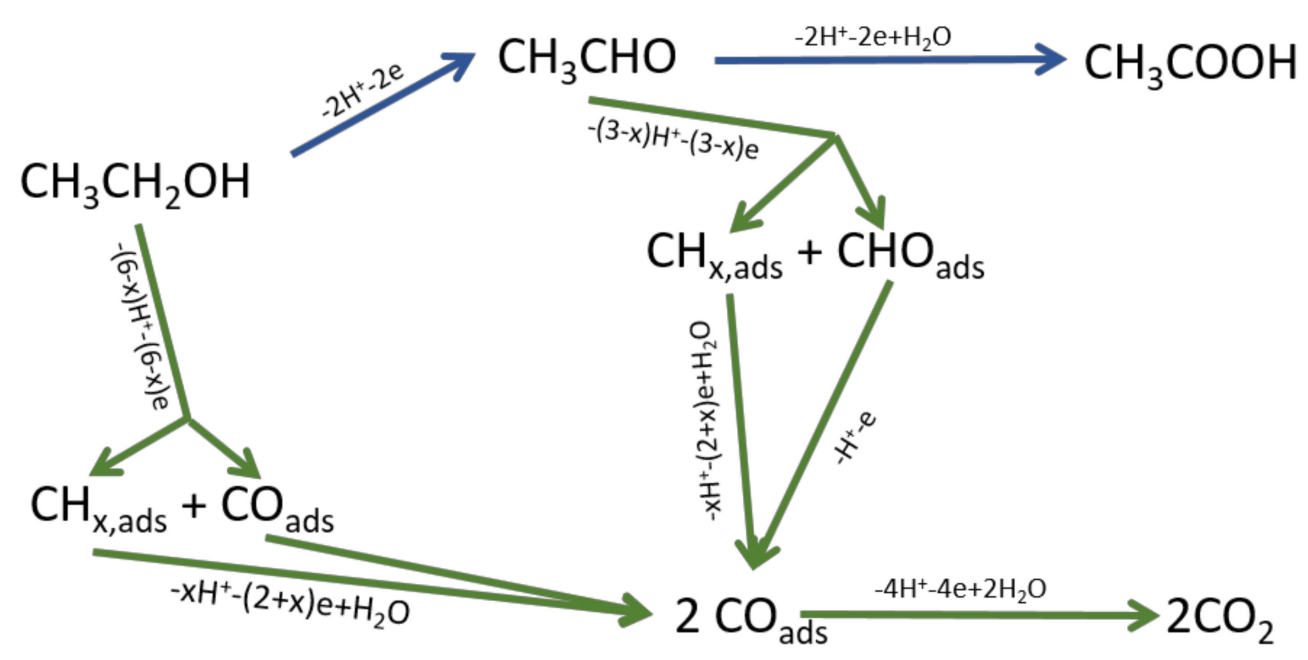

Figure 1. The parallel pathway of ethanol oxidation.

Nowadays, the oxidation of alcohols, like ethanol, in alkaline media has gained attention since non-Pt-based catalysts, such as Pd-based catalysts, can be used as the electrocatalyst for the oxidation and reduction reaction [21]. These alternative catalysts may decrease the cost of DEFCs and facilitate their commercialization [22,23]. The prevailing mechanism of the EOR produces acetaldehyde through the cleavage of the $\mathrm{C}-\mathrm{H}$ bond, which can undergo the aldol condensation reaction in alkaline media. When the aldol condensation reaction is faster than acetaldehyde oxidation to produce acetate the catalyst surface with $\beta$-hydroxy aldehyde. Since the electrocatalytic activity of materials is connected to their composition and morphology, replacement of Pt with other elements such as Pd not only mitigates the catalyst poisoning but may also decrease the cost. Mono and bimetallic Pt and Pd nanoparticles have been used for the electrocatalytic oxidation of ethanol. In all these studies, PtPd nanoparticles on different supports show better electrocatalytic properties than pure Pt or Pd nanoparticles [23-32]. However, due to the different criteria for comparing the electrocatalytic activity of these electrodes and the variety of supports, it is not clear which is the optimal composition for the EOR. On the other hand, there is a doubt about the electrocatalytic activity of Pt and Pd nanoparticles towards EOR. While some of these studies demonstrate the higher activity of Pd nanoparticles judging from onset potential and current density, other studies exhibit the lower onset potential for ethanol oxidation on the surface of Pt nanoparticles. In this regard, the evaluation of the electrocatalytic activity of $\mathrm{Pt}$ and $\mathrm{Pd}$ and the determination of the best composition of bimetallic PtPd nanoparticles for EOR in the alkaline media are controversial issues and the essential needs to produce practical DEFCs. The main objective of this study is to provide new insights to solve this debate by using a set of nanoparticles with different 
Pt:Pd rations synthesized in the same conditions and with very similar sizes. Thus, the EOR has been studied on mono and bimetallic Pt and Pd nanoparticles synthesized with a water-in-oil microemulsion method. Techniques such as transmission electron microscopy (TEM), energy-dispersive $X$-ray analysis (EDX), X-ray diffraction spectroscopy (XRD), and $\mathrm{X}$-ray photoelectron spectroscopy (XPS) are used to properly characterize the different nanoparticles in term of size, bulk and atomic compositions and structure. Electrochemical techniques including cyclic voltammetry (CV) and chronoamperometry (CA) are used to explore the catalytic activity, stability, and blocking species during EOR on the surface of the synthesized nanoparticles under alkaline conditions.

\section{Experimental}

\subsection{Materials and Methods}

Analytical grade of ethanol ( $\mathrm{EtOH}, 99.5 \%$ ), and $\mathrm{NaOH}$ were purchased from Merck (Darmstadt, Germany). $\mathrm{H}_{2} \mathrm{PtCl}_{6}, \mathrm{~K}_{2} \mathrm{PdCl}_{4}$, and $\mathrm{NaBH}_{4}$ were purchased from Sigma Aldrich (St. Louis, MO, USA). The aqueous solutions were prepared with ultrapure water. Electrochemical experiments were performed on a standard three-electrode cell system including a modified glassy carbon electrode (2 $\mathrm{mm}$ in diameter, GCE), Pt wire, and a saturated $\mathrm{Ag} / \mathrm{AgCl}$ as working, counter and reference electrodes, respectively. Electrochemical experiments were carried out with a $\mu$-Autolab potentiostat/galvanostat 101 controlled by Nova software (Metrohm, Switzerland).

The morphology and structure of the synthesized nanoparticles were studied by using an energy dispersive spectrometer (EDX, OXFORD, INCA model system, Oxford Instruments, Oxon, UK), transmission electron microscopy (TEM, JEOL JEM-2010 microscope working at $200 \mathrm{kV}$, JEOL, Tokyo, Japan), X-ray diffraction spectroscopy (XRD, Bruker D8 advance diffractometer, using $\mathrm{Cu} \mathrm{K} \alpha$ radiation, Bruker, Billerica, MA, USA), and X-ray photoelectron spectroscopy (XPS, VG Microtech Multilab electron spectrometer, Thermo Fisher Scientific, Waltham, MA, USA) methods.

\subsection{Synthesis of Nanoparticles and Modification of GCE}

The mono and bimetallic Pt and Pd nanoparticles with different atomic composition and rather uniform size were synthesized with a water-in-oil microemulsion (water/polyethylene glycol dodecyl ether $\left(\mathrm{Brij}^{\circledR} 30\right) / \mathrm{n}$-heptane) method according to previous works $[33,34]$. The synthesis was achieved by mixing equal volumes of the two microemulsions containing an aqueous solution of the metallic precursors and hydrazine as the reducing agent. In order to have micelles of the same size, i.e., nanoparticles of approximately the same size, the water to surfactant $\left(\omega_{0}=3.8\right)$ molar ratio and the surfactant concentration were maintained constant. After reduction, nanoparticles were precipitated by adding $\mathrm{NaOH}$ and the precipitated metallic nanoparticles were washed several times with acetone and finally kept in ultra-pure water as a suspension. For the preparation of alloyed nanoparticles, an aqueous solution of $\mathrm{H}_{2} \mathrm{PtCl}_{6} / \mathrm{K}_{2} \mathrm{PdCl}_{4}$ with a convenient atomic proportion of the two elements was employed. Before testing, the GCE was polished with $\mathrm{Al}_{2} \mathrm{O}_{3}$ powder (Sigma Aldrich, $45 \mu \mathrm{m}$ ), rinsed with distilled water, and dried at a temperature of $40{ }^{\circ} \mathrm{C}$. This mechanically cleaning was performed to remove the nanoparticles from prior experiments. The synthesized nanoparticles were ultrasonically suspended in double distilled water and the surface of clean GCE was covered homogenously with $5 \mu \mathrm{L}$ ink of each nanoparticle sample. The modified GCE was used as the working electrode after drying at a temperature of $40^{\circ} \mathrm{C}[20,33,35-37]$. The synthesized nanoparticles were denoted as the $\mathrm{Pt}, \mathrm{Pt}_{4} \mathrm{Pd}, \mathrm{Pt}_{3} \mathrm{Pd}_{2}, \mathrm{Pt}_{2} \mathrm{Pd}_{3}, \mathrm{PtPd}_{4}$, and $\mathrm{Pd}$ which correspond to a theoretical Pt:Pd ratio of 100:0, 80:20, 60:40, 40:60, 20:80, and 0:100, respectively.

\section{Results and Discussion}

\subsection{Characterization of the Nanoparticles}

Figure 2 shows some representative TEM images of the synthesized nanoparticles with different compositions. As can be seen, nanoparticles have a diameter below $5 \mathrm{~nm}$ 
(Figure 2a-f), with no significant changes in the morphology of the nanoparticles. In fact, the analysis of the structure of the nanoparticles carried out by TEM showed no visible differences due to the small difference between the lattice parameter of $\mathrm{Pt}$ and Pd nanoparticles, which is beyond the resolution of the images [23]. The mean particle size of the nanoparticles is reported in Table 1. This mean particle size was obtained from the analysis of more than 200 nanoparticles per sample from different parts of the grid and using ImageJ (Wayne Rasband, public domain) and Origin software (OriginLab, Northampton, MA, USA). The average size of synthesized nanoparticles according to the analysis of the TEM images is $3.4 \pm 1 \mathrm{~nm}$, and the biggest and smallest particle sizes were observed for the Pt and Pd nanoparticles with $4.5 \pm 0.7 \mathrm{~nm}$ and $1.6 \pm 0.4 \mathrm{~nm}$, respectively.
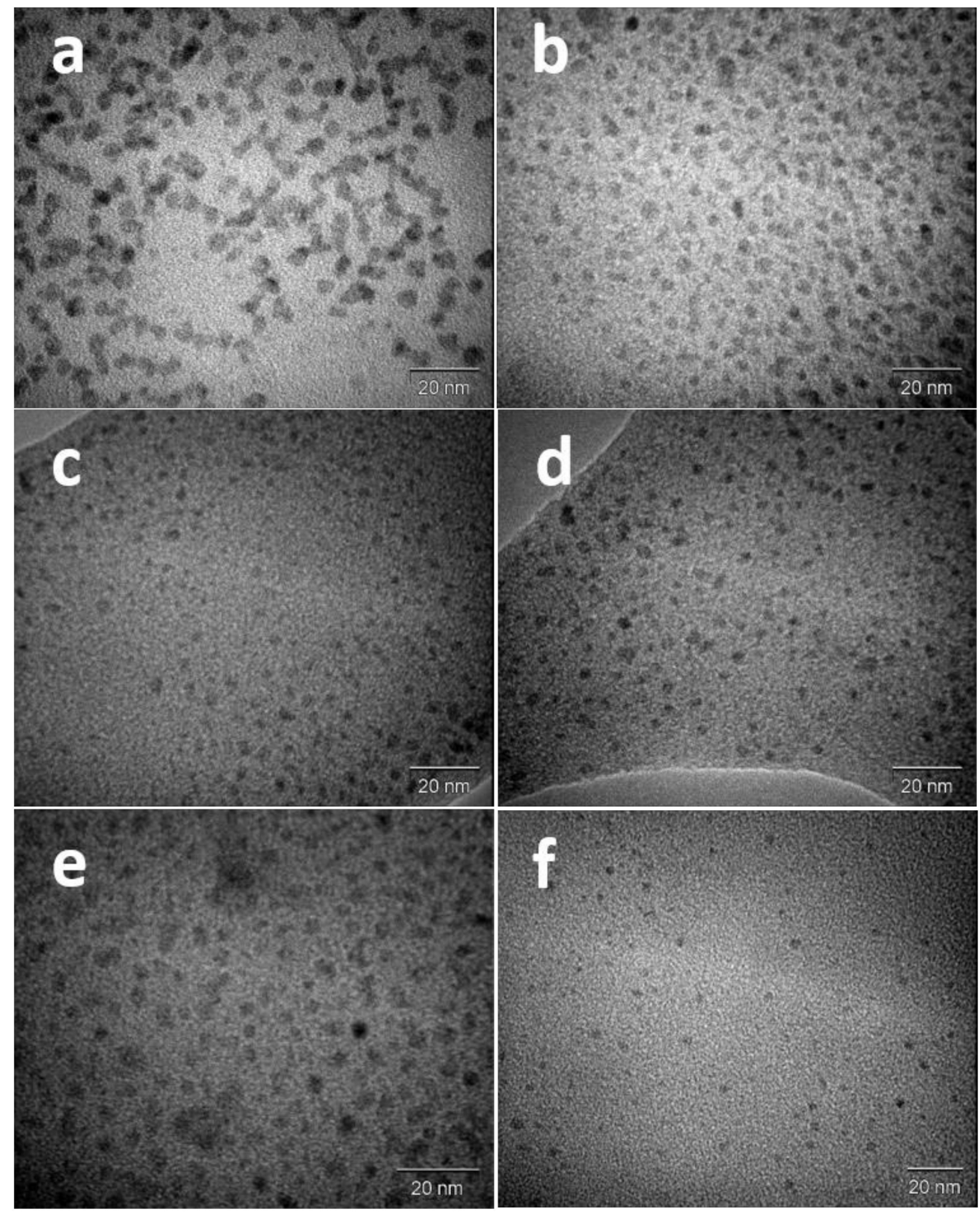

Figure 2. Representative transmission electron microscopy (TEM) micrographs of $\mathrm{Pt}(\mathbf{a}), \mathrm{Pt}_{4} \mathrm{Pd}(\mathbf{b})$, $\mathrm{Pt}_{3} \mathrm{Pd}_{2}(\mathbf{c}), \mathrm{Pt}_{2} \mathrm{Pd}_{3}(\mathbf{d}), \mathrm{PtPd}_{4}(\mathbf{e})$, and $\mathrm{Pd}(\mathbf{f})$ nanoparticles. 
Table 1. Mean particle size of the Pt, Pd, and PtPd nanoparticles employed in this work.

\begin{tabular}{ccc}
\hline Nominal Atomic Composition Pt/Pd & Particle Size (TEM)/nm & Particle Size (XRD)/nm \\
\hline $\mathrm{Pt}$ & $4.5 \pm 0.7$ & $3.2 \pm 0.4$ \\
$\mathrm{Pt}_{4} \mathrm{Pd}$ & $3.5 \pm 0.7$ & $3.8 \pm 0.4$ \\
$\mathrm{Pt}_{3} \mathrm{Pd}_{2}$ & $3.4 \pm 0.5$ & $4.2 \pm 0.4$ \\
$\mathrm{Pt}_{2} \mathrm{Pt}_{3}$ & $4.1 \pm 0.6$ & $4.9 \pm 0.5$ \\
$\mathrm{PtPd}_{4}$ & $3.4 \pm 0.5$ & $4 \pm 0.4$ \\
$\mathrm{Pd}$ & $1.6 \pm 0.4$ & $2.7 \pm 0.4$ \\
\hline
\end{tabular}

Figure 3 shows the XRD patterns of the different nanoparticles. All the diffraction peaks can be indexed with the face-centered cubic (fcc) bulk structure of $\mathrm{Pt}$ and $\mathrm{Pd}$. The nanoparticle size was also calculated by using the (200) lattice plane of the XRD measurements, using the Scherrer equation. The calculated sizes are also reported in Table 1 . The results obtained are in good agreement with the TEM analysis. In this respect, it should be noted that the estimation of the particle size with the XRD for particle sizes lower than $5 \mathrm{~nm}$ is always "approximate" and small discrepancies can be observed with those obtained by TEM since the averaging and definition of size is different.

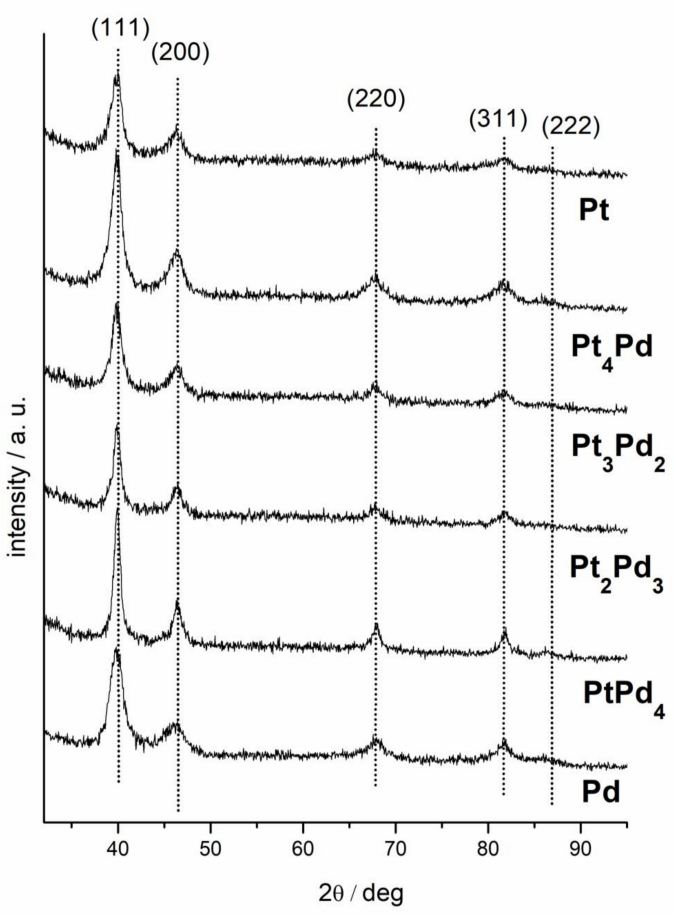

Figure 3. X-ray diffraction (WRD) patterns of the $\mathrm{Pt}, \mathrm{Pd}$, and $\mathrm{PtPd}$ nanoparticles employed in this work.

The real atomic composition of synthesized nanoparticles was calculated with AAS, UV-Vis, and EDX techniques. All of the calculated atomic compositions were in good agreement with the nominal values. The results have been represented in Table 2.

The XPS experiments were performed to determine the electronic properties of the nanoparticles, as shown in Figure 4. In some cases, XPS can also be used to characterize the surface composition. However, it is important to note that XPS is not a pure surface method because the electrons penetrate a few nanometers into the material. For nanoparticles with an average size of about $3.4 \mathrm{~nm}$, the spectra contain information from the whole nanoparticle [35]. We profit this property to determine the composition of synthesized nanoparticles by XPS [34]. The results are shown in the last column of Table 2. As can be seen, the values agree, within the error of the techniques, with the nominal values and those measured by AAS, UV-Vis, and EDX techniques. Regarding the electronic properties, 
the $\mathrm{Pt} 4 \mathrm{f}$ and $\mathrm{Pd} 3 \mathrm{~d}$ regions of the spectra are going to be examined. The $\mathrm{Pt} 4 \mathrm{f}$ peaks in the spectra of $\mathrm{Pt}_{1} \mathrm{Pt}_{4} \mathrm{Pd}$, and $\mathrm{PtPd}_{4}$ are shown in Figure $4 \mathrm{a}, \mathrm{c}, \mathrm{e}$. The deconvolution of the $\mathrm{Pt}$ $4 \mathrm{f}$ peaks shows two pairs of doublets. The pair located at $71 \mathrm{eV}\left(4 f_{7 / 2}\right)$ and $74.7 \mathrm{eV}\left(4 f_{5 / 2}\right)$ are attributed to $\mathrm{Pt}^{0}$ and the second pair at $72.9 \mathrm{eV}\left(4 f_{7 / 2}\right)$ and $76.4 \mathrm{eV}\left(4 f_{5 / 2}\right)$ are related to $\mathrm{Pt}^{2+}$ species. The analysis of the region corresponding to the $\mathrm{Pd} 3 \mathrm{~d}$ region displays very similar results. $\mathrm{Pd}^{0}$ shows a doublet with a binding energy of $335 \mathrm{eV}\left(3 d_{5 / 2}\right)$ and $341 \mathrm{eV}\left(3 d_{3 / 2}\right)$, whereas the pair of peaks at $337.1 \mathrm{eV}\left(3 d_{5 / 2}\right)$ and $342.8 \mathrm{eV}\left(3 d_{3 / 2}\right)$ are related to the presence of $\mathrm{Pd}^{2+}[38,39]$. The ratio of the intensity of $\mathrm{Pt}^{2+}$ and $\mathrm{Pt}^{0}$ (and also for $\mathrm{Pd}^{2+}$ and $\mathrm{Pd}^{0}$ ) proves that $\mathrm{Pt}$ and $\mathrm{Pd}$ are mostly in their reduced form. On the other hand, the analysis of the peak position indicates that the formation of the PtPd alloys modifies the peak positions. As the Pd ratio increases, the $\mathrm{Pt} 4 \mathrm{f}$ peaks shift to lower binding energies. On the other hand, the increase of the Pd ratio shifts the binding energy of $\mathrm{Pd} 3 \mathrm{~d}$ electrons to lower values. The changes in the binding energy observed with the Pt:Pd ratio demonstrates the change of electronic structure due to the formation of a PtPd alloy and the presence of electronic effects $[32,40]$.
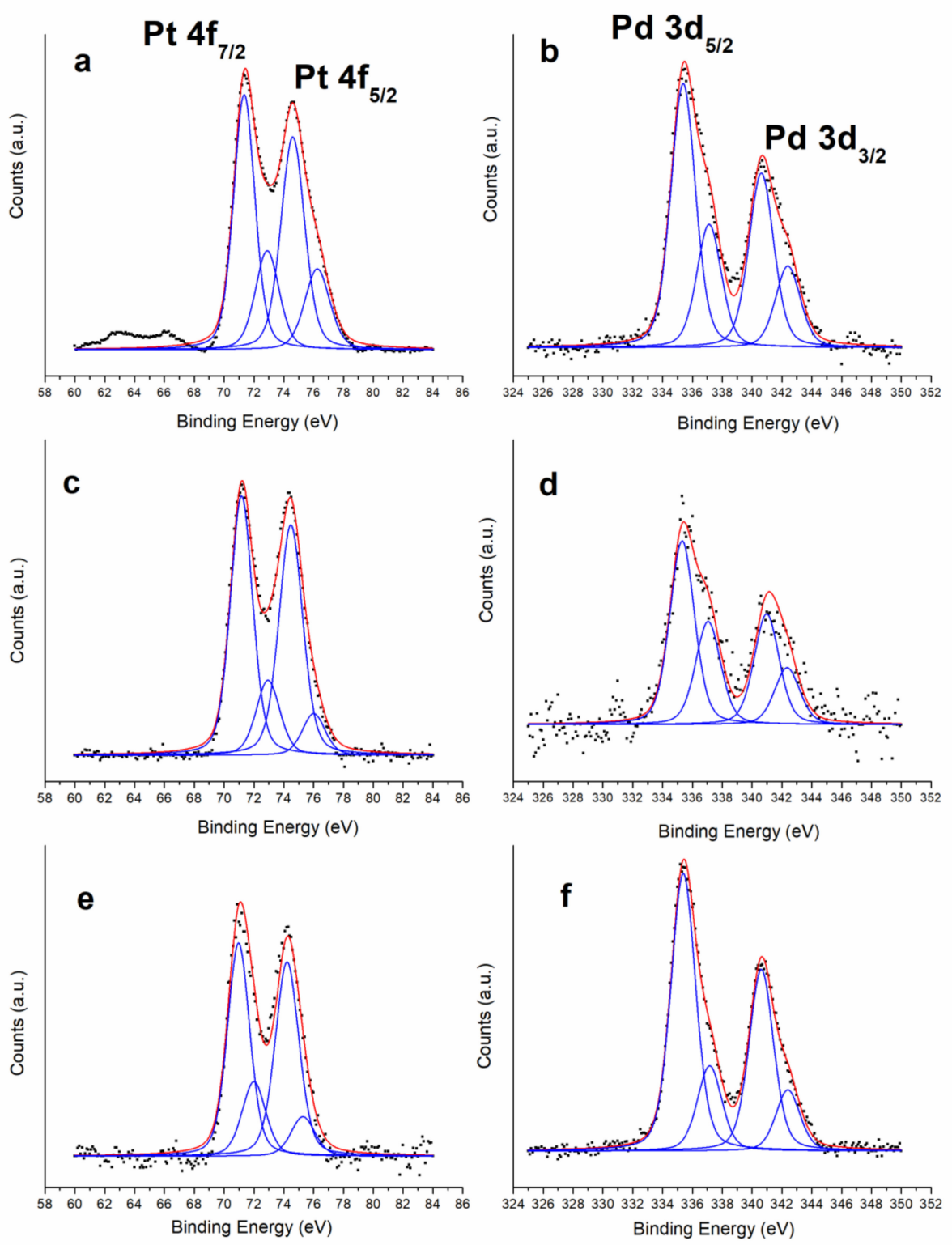

Figure 4. XPS spectra of Pt 4f for Pt (a), $\mathrm{Pt}_{4} \mathrm{Pd}(\mathbf{c}), \mathrm{PtPd}_{4}(\mathbf{e})$, and $\mathrm{Pd} 3 \mathrm{~d}$ for $\mathrm{Pd}(\mathbf{b}), \mathrm{Pt}_{4} \mathrm{Pd}(\mathbf{d})$, and $\mathrm{PtPd}_{4}(\mathbf{f})$. 
Table 2. Atomic composition of Pt/Pd nanoparticles obtained with the different analytical techniques.

\begin{tabular}{|c|c|c|c|}
\hline $\begin{array}{l}\text { Nominal Atomic } \\
\text { Composition } \mathrm{Pt} / \mathrm{Pd}\end{array}$ & $\begin{array}{c}\text { Calculated with } \\
\text { AAS }(P d) \text { UV-Vis }(P t)\end{array}$ & Calculated with EDX & $\begin{array}{l}\text { Calculated with XPS } \\
\operatorname{Pt}\left(4 f_{7 / 2}\right) \operatorname{Pd}\left(3 d_{5 / 2}\right)\end{array}$ \\
\hline $\mathrm{Pt}_{4} \mathrm{Pd}$ & $79.6 \pm 0.3 / 20.4 \pm 0.3$ & $82 \pm 0.5 / 18 \pm 0.5$ & $75.3 \pm 0.5 / 24.7 \pm 0.5$ \\
\hline $\mathrm{Pt}_{3} \mathrm{Pd}_{2}$ & $59.4 \pm 0.3 / 40.6 \pm 0.3$ & $62 \pm 0.5 / 38 \pm 0.5$ & $56.6 \pm 0.5 / 43.4 \pm 0.5$ \\
\hline $\mathrm{Pt}_{2} \mathrm{Pd}_{3}$ & $40.6 \pm 0.3 / 59.4 \pm 0.3$ & $40 \pm 0.5 / 60 \pm 0.5$ & $38 \pm 0.5 / 62 \pm 0.5$ \\
\hline $\mathrm{PtPd}_{4}$ & $17.8 \pm 0.3 / 82.2 \pm 0.3$ & $20.6 \pm 0.5 / 79.4 \pm 0.5$ & $21.4 \pm 0.5 / 78.6 \pm 0.5$ \\
\hline
\end{tabular}

\subsection{Electrochemical Experiments}

\subsubsection{Electrochemical Characterization: Background Examination in the Alkaline Media}

The electrochemical characterization of the nanoparticles was carried out by cyclic voltammetry in a $0.1 \mathrm{M} \mathrm{NaOH}$ solution at a scan rate of $0.05 \mathrm{~V} \mathrm{~s}^{-1}$ (Figure $5 \mathrm{a}-\mathrm{f}$ ). The sharpness, good definition, and the symmetry of the adsorption states in all nanoparticles are clear evidence of the effective surface cleanliness [36,37,41-44]. The observed signals in the profiles correspond to hydrogen ad(b)sorption-desorption $\left(\mathrm{H}_{\mathrm{ad}(\mathrm{b}) \mathrm{s}}-\mathrm{H}_{\mathrm{des}}\right), \mathrm{OH}$ adsorption $\left(\mathrm{OH}_{\mathrm{ads}}\right)$, metal oxidation, and reduction processes. The position and definition of those signals depend on the ratio of $\mathrm{Pt}: \mathrm{Pd}$ in the synthesized nanoparticles. For the pure $\mathrm{Pt}$ nanoparticles, the pairs of peaks in the positive potential sweep $\left(\mathrm{a}_{1}, \mathrm{a}_{2}\right)$ and their symmetric pairs of peaks in the negative potential sweep $\left(\mathrm{a}_{1}{ }^{\prime}, \mathrm{a}_{2}{ }^{\prime}\right)$ corresponds to the desorption and the adsorption of $\mathrm{H}$ on the surface of $\mathrm{Pt}$ nanoparticles, respectively $[20,29,36]$. On the other hand, the formation of $\mathrm{H}_{\mathrm{abs}}$ and $\mathrm{H}_{\mathrm{ads}}$ on the surface of $\mathrm{Pd}$ nanoparticles takes place in a single peak in the negative potential sweep $\left(b_{1}{ }^{\prime}\right)$, whereas the desorption of $H_{a b s}$ and $\mathrm{H}_{\mathrm{ads}}$ split into two peaks $\left(\mathrm{b}_{1}, \mathrm{~b}_{2}\right)$ in the positive scan direction (Figure $\left.5 \mathrm{f}\right)$ [45-49]. The $\mathrm{OH}$ adsorption, oxidation of $\mathrm{Pt}-\mathrm{OH}$ to $\mathrm{Pt}-\mathrm{O}$, and reduction of $\mathrm{PtO}$ to $\mathrm{Pt}$ are associated with peaks $\mathrm{a}_{3}, \mathrm{a}_{4}$, and $\mathrm{a}_{4}{ }^{\prime}$, respectively, in Figure $5 \mathrm{a}$. On $\mathrm{Pd}$, the adsorption of $\mathrm{OH}$ is not well defined, and the process corresponding to the Pd oxidation/reduction processes are marked by peaks $b_{3}$ and $b_{3}{ }^{\prime}$. The comparison between Figure $5 a$ and $\mathrm{f}$ demonstrates the reduction of $\mathrm{PtO}\left(\mathrm{a}_{4}{ }^{\prime}\right)$ takes place at more positive potential than that of $\mathrm{PdO}\left(\mathrm{b}_{3}{ }^{\prime}\right)$ on the nanoparticles. The potential values of the $\mathrm{Pt}(\mathrm{Pd}) \mathrm{O}$ reduction peak of the synthesized nanoparticles have been compared in the 4 th column of Table 3 . This observation reveals a higher tendency towards surface oxidation for Pd than for Pt nanoparticles [50]. Although the reduction of metal oxide represents a sharp peak on the surface of Pd nanoparticles (Figure $5 \mathrm{f}$ ), the reduction of metal oxide exhibits a broader peak at more positive potentials on the surface of $\mathrm{Pt}$ nanoparticles (Figure 5a). This process can be also understood from the comparison between values of width at half height of $\mathrm{Pt}(\mathrm{Pd}) \mathrm{O}$ reduction peak reported in the 3rd column of Table $3[46,47,50]$. The peak asymmetry of the oxidation/reduction reaction of the Pt and Pd surfaces clearly indicates that these are irreversible processes. Thus, in this potential region, the actual surface state depends on the scan direction. For the bimetallic nanoparticles, as seen in Figure 5, the profile changes according to the Pt:Pd ratio. Although $\mathrm{a}_{1}$ and $\mathrm{a}_{1}{ }^{\prime}$ peaks are entirely separate from the peaks of $\mathrm{a}_{2}$ and $\mathrm{a}_{2}$ ' for the synthesized nanoparticles with Pt percentage above $80 \%$, they merge in a single peak as the $\mathrm{Pd}$ ratio increases $[33,37,51]$. The potential of the metal oxide formation also shifts according to the composition $[20,29,51,52]$.

Table 3. Values of the reduction peak of the Pt-Pd oxide for all the nanoparticles.

\begin{tabular}{cccc}
\hline Nanoparticles & $\mathbf{Q} / \mu \mathbf{C}$ & Width at Half Heigh/V & $\mathbf{E}_{\text {peak }} / \mathbf{V}$ \\
\hline $\mathrm{Pt}$ & 120.4 & 0.24 & 0.72 \\
$\mathrm{Pt}_{4} \mathrm{Pd}$ & 83.5 & 0.24 & 0.72 \\
$\mathrm{Pt}_{3} \mathrm{Pd}_{2}$ & 305.5 & 0.22 & 0.70 \\
$\mathrm{Pt}_{2} \mathrm{Pd}_{3}$ & 377.8 & 0.15 & 0.70 \\
$\mathrm{PtPd}_{4}$ & 64.1 & 0.15 & 0.70 \\
$\mathrm{Pd}$ & 25.0 & 0.10 & 0.67 \\
\hline
\end{tabular}



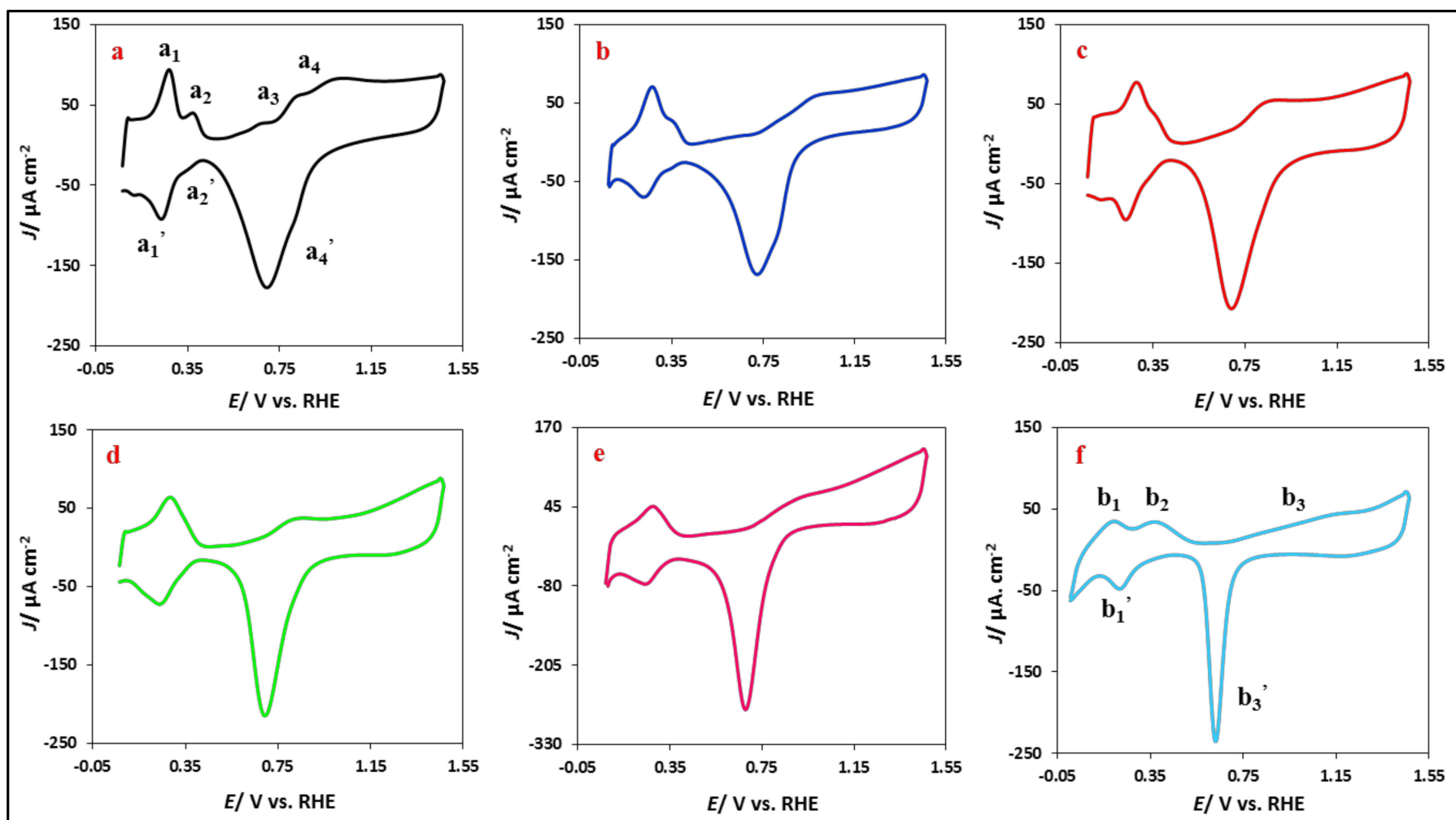

Figure 5. Voltammetric profile of the modified glassy carbon electrode (GCE) with (a) $\mathrm{Pt},(\mathbf{b}) \mathrm{Pt}_{4} \mathrm{Pd}_{2}(\mathbf{c}) \mathrm{Pt}_{3} \mathrm{Pd}_{2},(\mathbf{d}) \mathrm{Pt}_{2} \mathrm{Pd}_{3}$, (e) $\mathrm{PtPd}_{4}$, and (f) Pd nanoparticles in $0.1 \mathrm{M} \mathrm{NaOH}$ solution at the scan rate of $0.05 \mathrm{~V} \mathrm{~s}^{-1}$.

\subsubsection{Ethanol Electrooxidation: Potentiodynamic Measurements}

The catalytic properties of $\mathrm{Pt}_{1} \mathrm{Pt}_{4} \mathrm{Pd}_{1} \mathrm{Pt}_{3} \mathrm{Pd}_{2}, \mathrm{Pt}_{2} \mathrm{Pd}_{3}, \mathrm{PtPd}_{4}$, and $\mathrm{Pd}$ for the EOR were analyzed by voltammetry in a $0.1 \mathrm{M} \mathrm{NaOH}$ solution containing $0.1 \mathrm{M}$ ethanol, as shown in Figure 6. The analysis of the profiles aims to address these four issues: (1) the comparison between the intrinsic activity of $\mathrm{Pt}$ and Pd nanoparticles towards the EOR (2); the influence of the interfacial electronic structures of PtPd nanoparticles on EOR activity; (3) the trend of synthesized nanoparticles for the deactivation; and (4) the identification of the intermediate species which are responsible for the electrocatalyst poisoning and the current diminution upon cycling.

The specific activities were calculated via the normalizing of the currents to the active surface area of the nanoparticles [46]. As it is seen in Figure 6, the peaks attributed to $\mathrm{H}$ $\mathrm{ab}(\mathrm{d})$ sorption/desorption are suppressed and two well-defined anodic peaks appear in the forward and backward scans. The disappearance of the hydrogen peaks is attributed to the adsorption of the resultant ethoxy species, such as $\left(\mathrm{CH}_{3} \mathrm{CO}\right)_{\text {ads }}$, which blocks the electroactive sites. The activity for the positive scan direction reaches a maximum at ca. $0.8 \mathrm{~V}$ and then decrease as potential increases. The downfall of the current density corresponds to the formation of the Pd and Pt oxide layers, which block the adsorption of the reactive species onto the catalyst surface and lead to a decrease in the electrocatalytic activity. At $1.2 \mathrm{~V}$, the surface of the nanoparticles is completely covered with $\mathrm{PdO}$ or $\mathrm{PtO}$, which is inactive for the EOR, and the current density at this potential coincides with that recorded in absence of ethanol. When the scan is reversed and $\mathrm{PdO}$ or $\mathrm{PtO}$ is reduced, the electrode recovers its activity. This phenomenon results in the appearance of a peak in the negative scan direction [20,29]. There is a hysteresis between the positive and negative scan directions. First, the peak intensity is lower in the negative scan direction. This diminution can be due to two different reasons: (i), the surface in the negative scan direction is still partially covered by $\mathrm{PtO}$ or $\mathrm{PdO}$ and/or (ii) the surface has been poisoned by the polymerization of the acetaldehyde (which is the result of the partial oxidation of 
ethanol) through the aldol condensation. On the other hand, at ca. $0.5 \mathrm{~V}$, which is the onset of the EOR, currents in the negative scan direction are higher, which reveals that in the positive scan direction the surface may be blocked by some ethoxy adsorbed species, which have been oxidized at higher potentials. Regarding the evolution of the current densities with the PtPd ratio (Figure 6), PtPd binary catalysts exhibit considerable improvements over pure Pt and Pd [22,53]. In other words, the electrocatalytic activity of Pt nanoparticles improves by the incorporation of $\mathrm{Pd}$ on the nanoparticle and reaches a maximum at a $\mathrm{Pt}: \mathrm{Pd}$ ratio of 60:40. Not only peak currents are higher but also the onset potential diminishes. After that ratio, the electrocatalytic activity of PtPd nanoparticles decreases. These results are in good agreement with the reports by other groups [20,53].

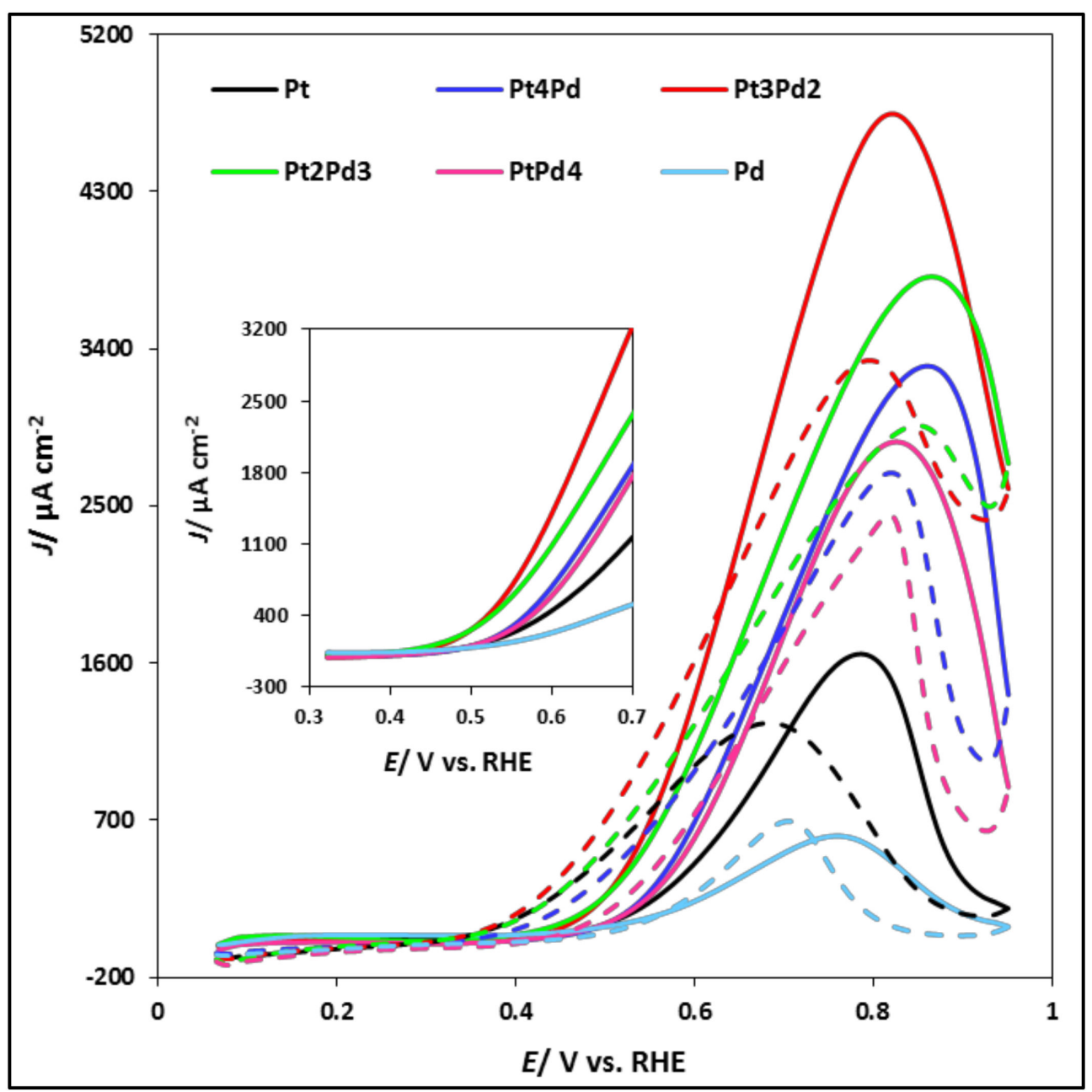

Figure 6. Cyclic voltammograms of the synthesized nanoparticles in a $0.1 \mathrm{M} \mathrm{NaOH}$ solution containing $0.1 \mathrm{M} \mathrm{EtOH}$ at a scan rate of $0.05 \mathrm{~V} \mathrm{~s}^{-1}$.

In the following, the stability of the electrocatalytic activity of the nanoparticles was assessed by comparing the currents recorded in the first voltammetric scan with those recorded after 20 scans (Figure 7). The residual specific activities increase from $18.4 \%$ for the $\mathrm{Pt}$ nanoparticles to $65 \%$ for the $\mathrm{Pt}_{3} \mathrm{Pd}_{2}$ nanoparticles, implying that these nanoparticles have the best poison resistance property. When the ratio of $\mathrm{Pd}$ on the nanoparticle composition exceeds $40 \%$, the residual activity decreases. This trend is in agreement with that obtained for the catalytic activity in the first scan. The electrocatalytic activity and poison resistance properties of the synthesized nanoparticles obtained from Figures 6 and 7 are summarized in Figure 8. From this figure, several conclusions can be extracted. First, pure Pt is more active than $\mathrm{Pd}$ for the oxidation of ethanol, although it shows a lower poison resistance. Since the decrease of the catalytic activity upon cycling is linked to the polymerization of 
acetaldehyde $[19,20,54,55]$, a lower deactivation rate indicates a higher efficiency in the oxidation of acetaldehyde to acetate. This fact implies that $\mathrm{Pt}$ is more active in the first step in the formation of acetaldehyde, but the oxidation of acetaldehyde to acetate seems to be more facile on $\mathrm{Pd}$. The further oxidation of acetaldehyde to acetate requires the transfer of an oxygen group. As shown in Figure 5, Pd oxide is formed at a lower potential than the $\mathrm{Pt}$ oxide. Since the previous step in the surface oxidation is the adsorption of $\mathrm{OH}$, $\mathrm{OH}$ adsorption on $\mathrm{Pd}$ should take place also at a lower potential, probably just after the desorption of hydrogen. Thus, the higher amount of adsorbed $\mathrm{OH}$ on the surface facilitates the second step. The increase of the electrocatalytic activity and poison resistance with the incorporation of $\mathrm{Pd}$ on the Pt nanoparticles should be then connected to a bifunctional effect. Pt atoms are effective in the dehydrogenation step to yield $\mathrm{CH}_{3} \mathrm{CO}_{\text {ads }}$ and then Pd surface atoms transfer the required oxygen group required to form acetate. This effect explains the higher currents measured in the first scan because the presence of Pd increases the effective number of electrons transferred in the oxidation and the higher poison resistance. For pure Pt nanoparticles, the main product is acetaldehyde, and the mean number of electrons is close to two. When Pd is added, the oxidation of acetaldehyde to acetate is facilitated which has two effects: (i) the mean number of transferred electrons increases with the concomitant current increase and (ii) the polymerization rate of acetaldehyde, which is responsible for the current diminution upon cycling, diminishes.
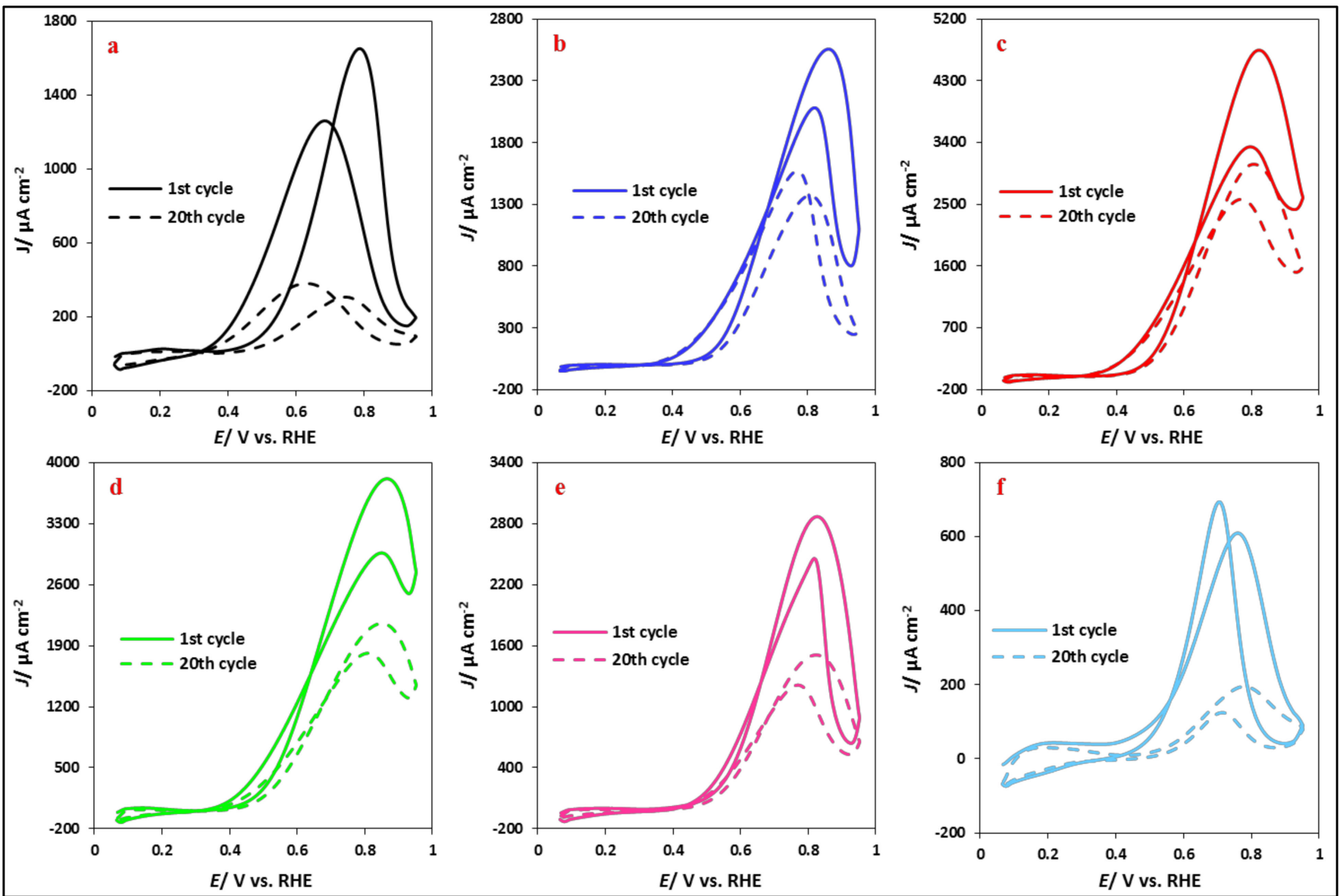

Figure 7. Comparison of the first and twentieth voltammograms for the oxidation of $0.1 \mathrm{M} \mathrm{EtOH}$ in $0.1 \mathrm{M} \mathrm{NaOH}$ solution for (a) $\mathrm{Pt},(\mathbf{b}) \mathrm{Pt}_{4} \mathrm{Pd}$, (c) $\mathrm{Pt}_{3} \mathrm{Pd}_{2}$, (d) $\mathrm{Pt}_{2} \mathrm{Pd}_{3}$, (e) $\mathrm{PtPd}_{4}$ and (f) $\mathrm{Pd}$ nanoparticles at a scan rate of $50 \mathrm{mV} \mathrm{s}^{-1}$. 


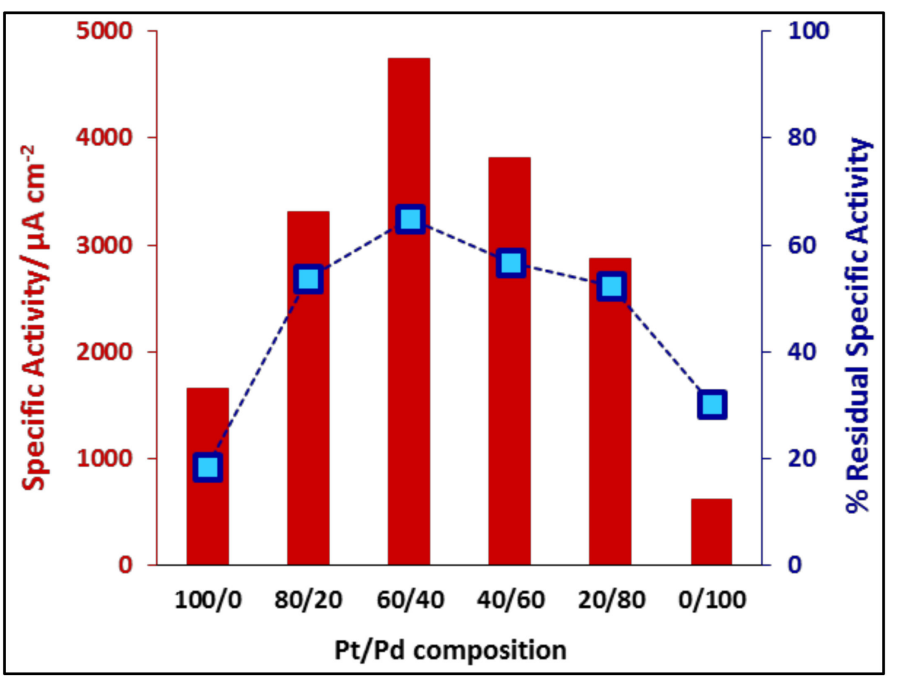

Figure 8. Evolution with the nanoparticle composition of the specific activity (red histogram) and residual specific activity after 20 consecutive cycles (blue line) for the EOR. Data obtained from Figures 6 and 7.

\subsubsection{Ethanol Electrooxidation: Potentiostatic Measurements}

In order to consider the stability of mono and bimetallic $\mathrm{Pt}$ and $\mathrm{Pd}$ nanoparticles towards ethanol oxidation in the alkaline media, the chronoamperometric experiments were performed at a constant potential of $0.56 \mathrm{~V}$ vs. RHE. This potential was selected since the electrocatalytic oxidation of ethanol has been begun at this potential, but the current is not controlled by the ethanol diffusion, so that any diminution of the current cannot be attributed to this phenomenon $[19,20]$. Figure 9 shows the transients measured at $0.56 \mathrm{~V}$ for each nanoparticle sample for $1000 \mathrm{~s}$. The general behavior of the transients shows a fast current decay during the first minute followed by a quasi-steady state in the middle region. Additionally, the reactivity trend follows the same behavior as that recorded in Figures 6 and 7. The highest and lowest current densities during CA experiments are obtained for $\mathrm{Pt}_{3} \mathrm{Pd}_{2}$ and $\mathrm{Pd}$ nanoparticles, respectively. The highest ratio of the current at $1000 \mathrm{~s}$ to the initial current corresponds to the $\mathrm{Pt}_{3} \mathrm{Pd}_{2}$ nanoparticles. This result indicates that the general behavior obtained for the voltammetry is also applicable to the potentiostatic currents, that is, PtPd alloy acts as a bifunctional catalyst in which Pt sites are used to dehydrogenate ethanol to produce acetaldehyde, and $\mathrm{Pd}$ sites proved the oxygen group required to oxidize acetaldehyde to acetate.

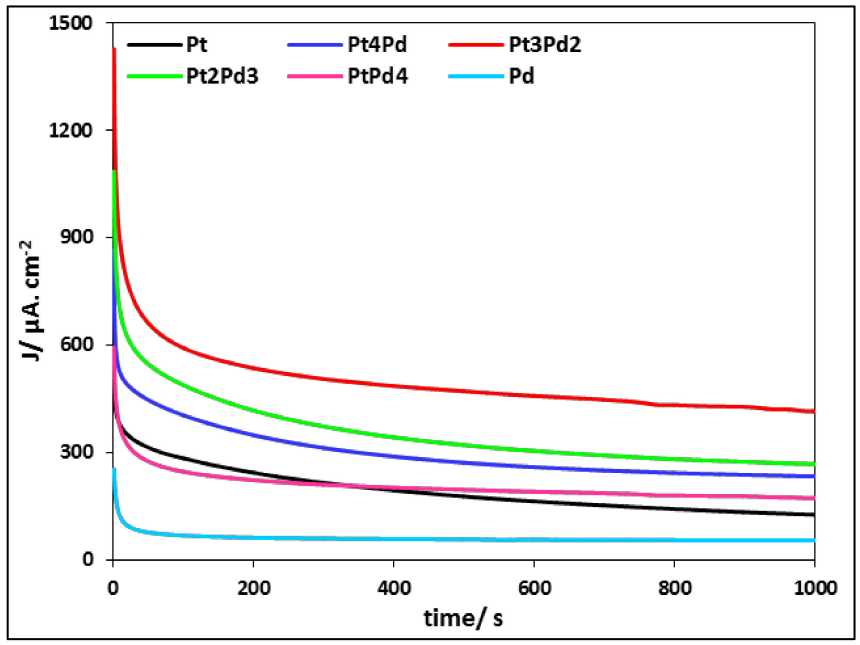

Figure 9. Chronoamperometric curves for the synthesized nanoparticles in $0.1 \mathrm{M} \mathrm{NaOH}$ solution containing $0.1 \mathrm{M} \mathrm{EtOH}$ at $0.56 \mathrm{~V}$. 


\section{Conclusions}

In this study, mono and bimetallic Pt and Pd nanoparticles were synthesized and their electrocatalytic activity towards ethanol oxidation in the alkaline media was studied. In the behavior of the synthesized nanoparticles, the electrocatalytic activity, and poisoning resistance properties were analyzed. The results indicated that the highest electrocatalytic activity and poison resistance for the EOR in alkaline media is obtained for the $\mathrm{Pt}_{3} \mathrm{Pd}_{2}$ nanoparticles. The acetaldehyde-acetate route was in all cases the dominant path for ethanol oxidation in the alkaline media and the PtPd nanoparticles act as a bifunctional catalyst.

Author Contributions: Conceptualization and supervision, J.S.-G. and E.H.; methodology, M.A.K., J.S.-G. and E.H., formal analysis M.A.K., J.S.-G. and E.H.; investigation, S.J., M.A.K., and J.S.-G.; writing—original draft preparation, S.J. and M.A.K.; writing—review and editing, M.A.K.; J.S.-G. and E.H. All authors have read and agreed to the published version of the manuscript.

Funding: This research was funded by Ministerio de Ciencia e Innovación (Spain) grant number PID2019-105653GB-100), Generalitat Valenciana (Spain) grant number PROMETEO/2020/063, and the University of Zanjan Research Council.

Institutional Review Board Statement: Not applicable.

Informed Consent Statement: Not applicable.

Data Availability Statement: The data presented in this study are available on request from the corresponding author.

Conflicts of Interest: The authors declare no conflict of interest.

\section{References}

1. Inci, M.; Türksoy, O. Review of fuel cells to grid interface: Configurations, technical challenges and trends. J. Clean. Prod. 2019, 213, 1353-1370. [CrossRef]

2. Rana, M.; Patil, P.K.; Chhetri, M.; Dileep, K.; Datta, R.; Gautam, U.K. Pd-Pt alloys nanowires as support-less electrocatalyst with high synergistic enhancement in efficiency for methanol oxidation in acidic medium. J. Colloid Interface Sci. 2016, 463, 99-106. [CrossRef] [PubMed]

3. Huang, L.; Zhang, X.; Wang, Q.; Han, Y.; Fang, Y.; Dong, S. Shape-Control of Pt-Ru nanocrystals: Tuning surface structure for enhanced electrocatalytic methanol oxidation. J. Am. Chem. Soc. 2018, 140, 1142-1147. [CrossRef] [PubMed]

4. Ong, B.C.; Kamarudin, S.K.; Basri, S. Direct liquid fuel cells: A review. Int. J. Hydrogen Energy 2017, 42, 10142-10157. [CrossRef]

5. Fadzillah, D.M.; Kamarudin, S.K.; Zainoodin, M.A.; Masdar, M.S. Critical challenges in the system development of direct alcohol fuel cells as portable power supplies: An overview. Int. J. Hydrog. Energy 2019, 44, 3031-3054. [CrossRef]

6. Christensen, P.A.; Jones, S.W.M. An in situ FTIR study of ethanol oxidation at polycrystalline platinum in $0.1 \mathrm{M} \mathrm{KOH}$ at 25 and $50^{\circ}$ C. J. Phys. Chem. C 2014, 118, 29760-29769. [CrossRef]

7. Jua, K.J.; Liu, L.; Feng, J.J.; Zhang, Q.L.; Wei, J.; Wang, A.J. Bio-Directed one-pot synthesis of Pt-Pd alloyed nanoflowers supported on reduced graphene oxide with enhanced catalytic activity for ethylene glycol oxidation. Electrochim. Acta 2016, 188, 696-703. [CrossRef]

8. Qian, W.; Wilkinson, D.P.; Shen, J.; Wang, H.; Zhang, J. Architecture for portable direct liquid fuel cells. J. Power Sources 2006, 154, 202-213. [CrossRef]

9. Li, N.H.; Sun, S.G. In situ FTIR spectroscopic studies of the electrooxidation of $\mathrm{C}_{4}$ alcohol on a platinum electrode in acid solutions Part, I. Reaction mechanism of 1-butanol oxidation. J. Electroanal. Chem. 1997, 436, 65-72.

10. Jin, Z.; Wang, Q.; Zheng, W.; Cui, X. Highly ordered periodic $\mathrm{Au} / \mathrm{TiO}_{2}$ hetero-nanostructures for plasmon-induced enhancement of the activity and stability for ethanol electro-oxidation. ACS Appl. Mater. Interfaces 2016, 8, 5273-5279. [CrossRef]

11. Kamyabi, M.A.; Mohammadian, H.; Jadali, S.; Moharramnezhad, M. Hydrothermal syntheses of NiO-GO nanocomposite on 3D nickel foam as a support for Pt nanoparticles and its superior electrocatalytic activity towards methanol oxidation. Electroanalysis 2019, 31, 1484-1493. [CrossRef]

12. Kamyabi, M.A.; Nosratabad, E.T.; Jadali, S. A Pt-Polymer nanocomposite as the excellent electro-catalyst: Synthesis, characterization, and electrochemical behavior towards methanol oxidation in the alkaline media. Synth. Met. 2019, 255, 116110-116117. [CrossRef]

13. Kamyabi, M.A.; Ebrahimi Qaratapeh, K.; Jadali, S.; Moharramnezhad, M. Decorating the carbon felt electrode with polymeric platinize nanocomposite: Characterization and electrocatalytic activity towards methanol oxidation reaction. J. Chem. Sci. 2019, 131, 1-9. [CrossRef] 
14. Kamyabi, M.A.; Jadali, S. A sponge like Pd arrays on Ni foam substrate: Highly active non-platinum electrocatalyst for methanol oxidation in alkaline media. Mater. Chem. Phys. 2021, 257, 123626. [CrossRef]

15. Chumillas, S.; Busó-Rogero, C.; Solla-Gullón, J.; Vidal-Iglesias, F.J.; Herrero, E.; Feliu, J.M. Size and diffusion effects on the oxidation of formic acid and ethanol on platinum nanoparticles. Electrochem. Commun. 2011, 13, 1194-1197. [CrossRef]

16. Kowal, A.; Li, M.; Shao, M.; Sasaki, K.; Vukmirovic, M.B.; Zhang, J.; Marinkovic, N.S.; Liu, P.; Frenkel, A.I.; Adzic, R.R. Ternary $\mathrm{Pt} / \mathrm{Rh} / \mathrm{SnO}_{2}$ electrocatalysts for oxidizing ethanol to $\mathrm{CO}_{2}$. Nat. Mater. 2009, 8, 325-330. [CrossRef]

17. Li, M.; Zhou, W.P.; Marinkovic, N.S.; Sasaki, K.; Adzic, R.R. The role of rhodium and tin oxide in the platinum-based electrocatalysts for ethanol oxidation to $\mathrm{CO}_{2}$. Electrochim. Acta 2013, 104, 454-461. [CrossRef]

18. Figueiredo, M.C.; Santasalo-Aarnio, A.; Vidal-Iglesias, F.J.; Solla-Gullón, J.; Feliu, J.M.; Kontturi, K.; Kallio, T. Tailoring properties of platinum supported catalysts by irreversible adsorbed adatoms toward ethanol oxidation for direct ethanol fuel cells. Appl. Catal. B Environ. 2013, 140-141, 378-385. [CrossRef]

19. Busó-Rogero, C.; Herrero, E.; Feliu, J.M. Ethanol oxidation on Pt single-crystal electrodes: Surface-structure effects in alkaline Medium. ChemPhysChem 2014, 15, 2019-2028. [CrossRef]

20. Busó-Rogero, C.; Solla-Gullón, J.; Vidal-Iglesias, F.J.; Herrero, E.; Feliu, J.M. Oxidation of ethanol on platinum nanoparticles: Surface structure and aggregation effects in alkaline medium. J. Solid State Electrochem. 2016, 20, 1095-1106. [CrossRef]

21. Liang, Z.X.; Zhao, T.S.; Xu, J.B.; Zhu, L.D. Mechanism study of the ethanol oxidation reaction on palladium in alkaline media. Electrochim. Acta 2009, 54, 2203-2208. [CrossRef]

22. Cheng, Y.; Guo, M.; Yu, Y.; Zhai, M.; Guo, R.; Hu, J. Fabrication of coral-like Pd based porous $\mathrm{MnO}_{2}$ nanosheet arrays on nickel foam for methanol electrooxidation. Ind. Eng. Chem. Res. 2018, 57, 10893-10904. [CrossRef]

23. Wang, J.; Cheng, N.; Banis, M.N.; Xiao, B.; Riese, A.; Sun, X. Comparative study to understand the intrinsic properties of Pt and Pd catalysts for methanol and ethanol oxidation in alkaline media. Electrochim. Acta 2015, 185, 267-275. [CrossRef]

24. Yang, X.; Yang, Q.; Xu, J.; Lee, C.S. Bimetallic PtPd nanoparticles on nafion-graphene film as catalyst for ethanol electro-oxidation. J. Mater. Chem. 2012, 22, 8057-8062. [CrossRef]

25. Ren, F.; Wang, H.; Zhai, C.; Zhu, M.; Yue, R.; Du, Y.; Yang, P.; Xu, J.; Lu, W. Clean method for the synthesis of reduced graphene oxide-supported PtPd alloys with high electrocatalytic activity for ethanol oxidation in alkaline medium. ACS Appl. Mater. Interfaces 2014, 6, 3607-3614. [CrossRef]

26. Chen, X.; Cai, Z.; Chen, X.; Oyama, M. Green synthesis of graphene-PtPd alloy nanoparticles with high electrocatalytic performance for ethanol oxidation. J. Mater. Chem. A 2014, 2, 315-320. [CrossRef]

27. Li, S.S.; Zheng, J.N.; Ma, X.; Hu, Y.Y.; Wang, A.J.; Chen, J.R.; Feng, J.J. Facile synthesis of hierarchical dendritic PtPd nanogarlands supported on reduced graphene oxide with enhanced electrocatalytic properties. Nanoscale 2014, 6, 5708-5713. [CrossRef]

28. Yang, G.; Zhou, Y.; Pan, H.B.; Zhu, C.; Fu, S.; Wai, C.M.; Du, D.; Zhu, J.J.; Lin, Y. Ultrasonic-assisted synthesis of Pd-Pt/carbon nanotubes nanocomposites for green enhanced electro-oxidation of ethanol and methanol in alkaline medium. Ultrason. Sonochem. 2016, 28, 192-198. [CrossRef]

29. Fan, J.; Qi, K.; Zhang, L.; Zhang, H.; Yu, S.; Cui, X. Engineering Pt/Pd interfacial electronic structures for highly efficient hydrogen evolution and alcohol oxidation. ACS Appl. Mater. Interfaces 2017, 9, 18008-18014. [CrossRef]

30. Huang, Z.; Zhou, H.; Chang, Y.; Fu, C.; Zeng, F.; Kuang, Y. Improved catalytic performance of Pd nanowires for ethanol oxidation by monolayer of Pt. Chem. Phys. Lett. 2013, 585, 128-132. [CrossRef]

31. Zhang, Q.; Chen, T.; Jiang, R.; Jiang, F. Comparison of electrocatalytic activity of $\mathrm{Pt}_{1-\mathrm{x}} \mathrm{Pd}_{\mathrm{x}} / \mathrm{C}$ catalysts for ethanol electro-oxidation in acidic and alkaline media. RSC Adv. 2020, 10, 10134-10143. [CrossRef]

32. Luo, W.; Zhou, H.; Fu, C.; Huang, Z.; Gao, N.; Kuang, Y. Preparation and characterization of porous sponge-like Pd@Pt nanotubes with high catalytic activity for ethanol oxidation. Mater. Lett. 2016, 173, 43-46. [CrossRef]

33. Solla-Gullón, J.; Rodes, A.; Montiel, V.; Aldaz, A.; Clavilier, J. Electrochemical characterisation of platinum/palladium nanoparticles prepared in a water-in-oil microemulsion. J. Electroanal. Chem. 2003, 554-555, 273-284. [CrossRef]

34. Solla-Gullón, J.; Montiel, V.; Aldaz, A.; Clavilier, J. Synthesis and electrochemical decontamination of platinum-palladium nanoparticles prepared by water-in-oil microemulsion. J. Electrochem. Soc. 2003, 150, E104-E109. [CrossRef]

35. Vidal-Iglesias, F.J.; Solla-Gullon, J.; Montiel, V.; Feliu, J.M.; Aldaz, A. Screening of electrocatalysts for direct ammonia fuel cell: Ammonia oxidation on PtMe (Me: Ir, Rh, Pd, Ru) and preferentially oriented Pt( $\left.\begin{array}{lll}1 & 0 & 0\end{array}\right)$ nanoparticles. J. Power Sources 2007, 171, 448-456. [CrossRef]

36. Vidal-Iglesias, F.J.; Aran-Ais, R.M.; Solla-Gullo, J.; Herrero, E.; Feliu, J.M. Electrochemical characterization of shape-controlled Pt nanoparticles in different supporting electrolytes. ACS Catal. 2012, 2, 901-910. [CrossRef]

37. Solla-Gullón, J.; Vidal-Iglesias, F.J.; Montiel, V.; Aldaz, A. Electrochemical characterization of platinum-ruthenium nanoparticles prepared by water-in-oil microemulsion. Electrochim. Acta 2004, 49, 5079-5088. [CrossRef]

38. Zhang, Y.; Zhao, L.; Walton, J.; Liu, Z.; Tang, Z. Facile fabrication of PtPd alloyed worm-like nanoparticles for electrocatalytic reduction of oxygen. Int. J. Hydrogen Energy 2017, 42, 17112-17121. [CrossRef]

39. Yang, Y.; Luo, L.M.; Guo, Y.F.; Dai, Z.X.; Zhang, R.H.; Sun, C.; Zhou, X.W. In situ synthesis of PtPd bimetallic nanocatalysts supported on graphene nanosheets for methanol oxidation using triblock copolymer as reducer and stabilizer. J. Electroanal. Chem. 2016, 783, 132-139. [CrossRef] 
40. Xue, Q.; Bai, J.; Han, C.; Chen, P.; Jiang, J.X.; Chen, Y. Au nanowires@Pd-polyethylenimine nanohybrids as highly active and methanol-tolerant electrocatalysts toward oxygen reduction reaction in alkaline media. ACS Catal. 2018, 8, 11287-11295. [CrossRef]

41. Farias, M.J.S.; Vidal-Iglesias, F.J.; Solla-Gullón, J.; Herrero, E.; Feliu, J.M. On the behavior of CO oxidation on shape-controlled Pt nanoparticles in alkaline medium. J. Electroanal. Chem. 2014, 716, 16-22. [CrossRef]

42. Montiel, M.A.; Vidal-Iglesias, F.J.; Montiel, V.; Solla-Gullón, J. Electrocatalysis on shape-controlled metal nanoparticles: Progress in surface cleaning methodologies. Curr. Opin. Electrochem. 2017, 1, 34-39. [CrossRef]

43. Solla-Gullón, J.; Montiel, V.; Aldaz, A.; Clavilier, J. Electrochemical and electrocatalytic behaviour of platinum-palladium nanoparticle alloys. Electrochem. Commun. 2002, 4, 716-721. [CrossRef]

44. Solla-Gullón, J.; Montiel, V.; Aldaz, A.; Clavilier, J. Electrochemical characterisation of platinum nanoparticles prepared by microemulsion: How to clean them without loss of crystalline surface structure. J. Electroanal. Chem. 2000, 491, 69-77. [CrossRef]

45. Guerin, S.; Attard, G.S. Electrochemical behavior of electrodeposited nanostructured palladium + platinum films in $2 \mathrm{M} \mathrm{H}_{2} \mathrm{SO}_{4}$. Electrochem. Commun. 2001, 3, 544-548. [CrossRef]

46. Alexeyeva, N.; Sarapuu, A.; Tammeveski, K.; Vidal-Iglesias, F.J.; Solla-Gullón, J.; Feliu, J.M. Electroreduction of oxygen on Vulcan carbon supported Pd nanoparticles and Pd-M nanoalloys in acid and alkaline solutions. Electrochim. Acta 2011, 56, 6702-6708. [CrossRef]

47. Erikson, H.; Sarapuu, A.; Alexeyeva, N.; Tammeveski, K.; Solla-Gullón, J.; Feliu, J.M. Electrochemical reduction of oxygen on palladium nanocubes in acid and alkaline solutions. Electrochim. Acta 2012, 59, 329-335. [CrossRef]

48. Pandey, R.K.; Lakshminarayanan, V. Electro-Oxidation of formic acid, methanol, and ethanol on electrodeposited Pd-polyaniline nanofiber films in acidic and alkaline medium. J. Phys. Chem. C 2009, 113, 21596-21603. [CrossRef]

49. Jiang, R.; Tran, D.T.; McClure, J.P.; Chu, D. A class of (Pd-Ni-P) electrocatalysts for the ethanol oxidation reaction in alkaline media. ACS Catal. 2014, 4, 2577-2586. [CrossRef]

50. Chen, Z.; He, Y.C.; Chen, J.H.; Fu, X.Z.; Sun, R.; Chen, Y.X.; Wong, C.P. PdCu alloy flower-like nanocages with high electrocatalytic performance for methanol oxidation. J. Phys. Chem. C 2018, 122, 8976-8983. [CrossRef]

51. Lin, Y.; Tian, N.; Xiao, C.; Sheng, T.; Li, G.; Zhang, F.; Ye, J.; Xu, B.; Zhou, Z.; Sun, S. Effects of atom arrangement and thickness of $\mathrm{Pt}$ atomic layers on Pd nanocrystals for electrocatalysis. Electrochim. Acta 2018, 271, 519-525. [CrossRef]

52. Ma, L.; Chu, D.; Chen, R. Comparison of ethanol electro-oxidation on Pt/C and Pd/C catalysts in alkaline media. Int. J. Hydrog. Energy 2012, 37, 11185-11194. [CrossRef]

53. Zhang, H.; Xu, L.; Tian, Y.; Jiao, A.; Li, S.; Liu, X.; Chen, M.; Chen, F. Convenient synthesis of 3D fluffy PtPd nanocorals loaded on 2D h-BN supports as highly efficient and stable electrocatalysts for alcohol oxidation reaction. ACS Omega 2019, 4, 11163-11172. [CrossRef] [PubMed]

54. Buso-Rogero, C.; Brimaud, S.; Solla-Gullon, J.; Vidal-Iglesias, F.J.; Herrero, E.; Behm, J.R.; Feliu, J.M. Ethanol oxidation on shape-controlled platinum nanoparticles at different pHs: A combined in situ IR spectroscopy and online mass spectrometry study. J. Electroanal. Chem. 2015, 763, 116-124. [CrossRef]

55. Busó-Rogero, C.; Solla-Gullón, J.; Vidal-Iglesias, F.J.; Herrero, E.; Feliu, J.M. Adatom modified shape-controlled platinum nanoparticles towards ethanol oxidation. Electrochim. Acta 2016, 196, 270-279. [CrossRef] 